\title{
Süt Sağım Makinelerinde Çalışma Vakumu ve Süt Debisi Değişimlerinin Ortalama Pençe Vakumuna Etkisi
}

\author{
Halil Ünal* Enes Tumba Dilek Kılıç iD Gaye Atı iD
}

Bursa Uludağ Üniversitesi, Ziraat Fakültesi, Biyosistem Mühendisliği Bölümü, 16059, Bursa

*Sorumlu yazar: hunal@uludag.edu.tr

Geliş Tarihi: 15.12.2019

Kabul Tarihi: 17.09.2020

\section{Öz}

Bu çalışmada 5 farklı tip süt pençesine (150, 240, 300, 340 ve $550 \mathrm{ml}$ hacimlerinde) sahip sağım başlıklarında çalışma vakumu ve süt debisi değişimlerinin alçak ve yüksek süt hatlı sağım tesislerinde ortalama pençe vakumuna etkisi araştırılmıştır. Süt pençeleri sağım demetindeki diğer tüm elemanlarının aynı olduğu 5 adet sağım başlığına bağlanmıştır. Sağım başlıklarındaki meme lastikleri uzun tip neopren kauçuk malzemedir. Araştırmada alçak süt hatlı sağım sistemi için 41, 44 ve $47 \mathrm{kPa}$, yüksek süt hatlı sağım sistemi için ise $50 \mathrm{kPa}$ çalışma vakumları seçilmiştir. Her vakum aşaması 6 farklı süt debisi $\left(0,0,7,2,7,4,7,6,6\right.$ ve 8,3 $\mathrm{kg} \mathrm{dk}^{-1}$ gerçekleştirilmiştir. Araştırma sonuçlarına göre, $41 \mathrm{kPa}$ çalışma vakumunda Pençe-2 (240 ml hacimdeki süt pençesi) en uygun ortalama pençe vakum aralıklarını vermiştir. $44 \mathrm{kPa}$ çalışma vakumunda $7,4 \mathrm{~kg}^{-1} \mathrm{dk}^{-1}$ debisine kadar Pençe-2 ve Pençe-4'ün (340 ml hacimdeki süt pençesi); $47 \mathrm{kPa}$ basınçta ise 2,7-6,5 $\mathrm{kg} \mathrm{dk}^{-1} \mathrm{süt}^{-}$ debisi aralıkları için Pençe-5'in (550 ml hacimdeki süt pençesi) ortalama pençe vakum düzeyleri daha uygun bulunmuştur. Yüksek süt hattındaki $50 \mathrm{kPa}$ çalışma vakumunda 2, 3 ve 4 nolu süt pençelerinin ortalama pençe vakumları diğer pençelere göre daha uygun görülmüştür.

Anahtar Kelimeler: Alçak ve yüksek hatlı sağım sistemleri, süt pençesi, kauçuk meme lastiği, pençe vakumu, süt debisi

\section{The Effect of Working Vacuum and Milk Flow Rate Variations on Average Claw Vacuum in Milking Machines \\ Abstract}

In this study, the effect of working vacuum and milk flow changes on the average claw vacuum in low and high milk line milking facilities in milking heads with 5 different types of milk claw (150, 240, 300, 340 and $550 \mathrm{ml}$ volumes) were investigated. Milk claws are connected to 5 milking clusters, where all other elements in the milking bundle are the same. The liners in the milking clusters are made of long type neoprene rubber. In the study, 41, 44 and $47 \mathrm{kPa}$ vacuum pumps were selected for low milk line milking system and $50 \mathrm{kPa}$ operating vacuum for high-line milking system. Each vacuum step was carried out at 6 different milk flows $(0,0.7,2.7$, 4.7, 6.6 and $\left.8.3 \mathrm{~kg} \mathrm{~min}^{-1}\right)$. According to the results of the study, Claw-2 (240 ml milk claw) at $41 \mathrm{kPa}$ working vacuum gave the optimum average claw vacuum intervals. Claw-2 and Claw 4 up to a milk flow rate of $7.4 \mathrm{~kg}$ $\min ^{-1}$ at $44 \mathrm{kPa}$ working vacuum (340 ml volume of milk claw); at $47 \mathrm{kPa}$ pressure, average claw vacuum levels of Claw-5 (550 ml milk claw) were found to be more suitable for the milk flow intervals of $2.7-6.5 \mathrm{~kg} \mathrm{~min}^{-1}$. The average claw vacuum of milk claws 2,3 and 4 was found more suitable than other claws at $50 \mathrm{kPa}$ working vacuum in high milk line.

Keywords: Low and high line milking systems, milk claw, rubber liner, claw vacuum, milk flow rate

\section{Giriş}

Meme sağlı̆̆ında herhangi bir zararlı etkiye neden olmadan hayvanın tüm sütünün en kısa sürede elde edilmesi için etkili bir sağım tekniği gereklidir. Sağım sisteminin inekler üzerindeki etkisinin en doğru ölçüsü pençedeki vakumdur (Reinemann ve ark., 2007). Sağım ünitesinin ana parametresi memebaşı ucu vakum basıncıdır. Memebaşı ucu vakum basıncı ne kadar yüksek olursa sağım hızı da o kadar yüksek olur, sağım süresi de bir o kadar kısalır. Ancak uygulamalarda vakum hattının üst sınırı $50 \mathrm{kPa}$ olarak kanıtlanmıştır (Rasmussen ve ark., 2003; Andersons ve ark., 2014). Yüksek vakum ile sağım, hayvan meme başlarında deformasyonun yanı sıra memede acıya neden olabilmektedir. Ayrıca, meme lastiği nabız odası vakumu ne kadar düşük olursa, meme sağlığı 
üzerindeki olumsuz etkileri de o kadar düşük olabilmektedir (Reinemann ve ark., 1996; Jones, 1999; Öz, 2003). Ancak, vakum için sınırlar da vardır. Çok alçak basınçta hayvan memebaşı ucu başlıktan çıkma eğiliminde olabilmekte ve sağım süresi uzunluğu da büyük ölçüde artmaktadır. Standartlarda en yüksek süt debilerinde nabız odası vakum düzeyinin $32-40 \mathrm{kPa}$ aralığında olması gerektiği bildirilmiştir (Rasmussen ve Madsen, 2000; TS ISO 5707, 2014). Bu vakum aralığ1 meme ucu sağlığ1 üzerinde negatif bir etki bırakmamakta, bunun yanı sıra arzu edilen sağım hızını ve hayvan memesinin başlıkta tutulmasını sağlamaktadır.

Modern sağım tesislerinde alçak ve yüksek hatlı süt sağım sistemleri kullanılmaktadır. TS ISO 6690:2007 (2014)'de test koşullarının belirlendiği Tablo A.2'ye göre yüksek hatlı sağım sistemlerinde süt hattı sağım platformundan 1,8 m'den veya süt hattı sağım başlığı (süt pençesi) konumundan 1,3 m'den daha üstte, alçak hatlı sistemlerde ise süt hattı sağım başlığı (süt pençesi) konumundan 0,7 m'den daha düşük seviyede yerleştirilmektedir. Her iki sistem için en önemli fark, sağımın farklı bir işlemde olmasıdır. Alçak hatı sistemde sağım sırasında hat boyunca akan süt, hattın altında bulunan pençeye yerçekimi kuvveti yardımıyla kendiliğinden akmaktadır. Yüksek hatlı sistemde ise, sütü hatta taşımak için süt hattı üzerinde ek enerjiye ihtiyaç vardır. Bunun için süt hattındaki vakum, meme başlığı vakumundan daha yüksek olmalıdır. Uzun süreli uygulamada, yüksek hatlı sağım sistemlerinde hatta süt akışı olmadığı zaman çalışma vakumu $50 \mathrm{kPa}$ olarak verilmiştir. Reinemann ve ark. (2007), iyi sağım özellikleri ve meme sağlığını sağlamak için sağım sırasında en yüksek sağım veriminde 36-42 kPa arasında bir süt pençesi vakumunun daha uygun olduğunu bildirmişlerdir. Bir ineğin en yüksek süt debisi süresi boyunca bu aralık içinde ortalama pençe vakumuna sahip olması; genellikle ineğin uysal bir şekilde, hızlı ve tam olarak sağımı için uygun bir aralık olduğu kabul edilir. Ancak Avrupa'da yaygın olarak kullanılan ortalama pençe vakumu için kurallar, Kuzey Amerika'da tavsiye edilenden biraz düşüktür. Bu ülkeler tipik olarak, 32 ila $40 \mathrm{kPa}$ aralığındaki en yüksek süt debisi periyodu sırasında ISO sağım makinesi standart ortalama pençe vakum standardında sunulan önerileri kullanmaktadır (Rose-Meierhöfer ve ark., 2010; TS ISO 5707:2007, 2014). Ortalama pençe vakumu için Avrupa ve Kuzey Amerika standart kuralları arasında biraz fark olsa da ortalama pençe vakumu belirlenirken her ikisi de nazikçe, hızlı ve tam sağım arasında bir uzlaşma kavramına dayanmaktadır. Çünkü yüksek ortalama pençe vakumu hızlı sağımı sağlar, ancak sağım nazik ve tamamıyla olamaz. Düşük ortalama pençe vakumu daha nazik ve eksiksiz sağım yapar, ancak hızlı olmayan bir sağıma neden olur. Buradan anlaşılabilmektedir ki, standartlarda yüksek ve alçak hatlı sistemlerdeki en uygun ortalama pençe vakum aralığının ne olması gerektiği sorusu cevapsız kalabilmektedir. Bu soru üzerindeki araştırma çalışmaları ve sağım makinaları kullanım talimatları önerilerinde büyük farklılıklar olduğu sonucuna varılmıştır. Buna göre, farklı sağım sistemleri bile sağım sırasında benzer bir ortalama pençe vakumu gerektirebilir. Bu durum, mevcut araştırma konusunun seçilmesinde etkili olmuştur. Bunu başarmak için, bu çalışmada farklı iç hacimlere sahip süt pençelerinde alçak süt hattı ve yüksek süt hattı sistemlerinin farklı basınç ayarları karşılaştııılmıştır.

$\mathrm{Bu}$ araştırmanın amac1, alçak süt hatlı (ASH) ve yüksek süt hatlı (YSH) süt sağım makinalarının farklı sistem çalışma vakumlarında (ASH'da 41, 44 ve $47 \mathrm{kPa}$; YSH'da $50 \mathrm{kPa}$ ) ve farkl1 süt debilerinde, farklı iç hacimlere sahip süt pençelerinin $(150,240,300,340$ ve $550 \mathrm{ml}$ ) "a+b" süt alım (emme) fazındaki ortalama pençe vakumu değişimlerinin etkisini belirlemektir.

\section{Materyal ve Yöntem}

Araştırma Bursa Uludağ Üniversitesi, Ziraat Fakültesi, Biyosistem Mühendisliği Bölümü laboratuvar koşullarında özel olarak tasarlanan ve süt yerine suyun kullanıldığı test düzeneğinde gerçekleştirilmiştir (Ünal ve ark., 2018). Test düzeneği ve elemanları Şekil 1'de verilmiştir.

Tasarlanan test düzeneğinde şebekeden alınan su (2) bir su deposuna (4) doldurulmaktadır. Depo içindeki su seviyesi bir şamandıra (3) ile kontrol edilmektedir. Depodaki su belirli bir doluluk seviyesinde iken doğal akışla yapay memeye (10) akmaktadır. Yapay meme olarak 5 L kapasiteli bir kova kullanılmıştır. Su deposu ve yapay meme arasına suyun kontrolü için bir vana (5) yerleştirilmiştir. Yapay memenin tabanında orta kısmına bir adet delik açılarak buraya dört yollu hortum yerleştirilmiş ve uç kısımlarına plastik malzemeden imal edilmiş 4 adet yapay meme ucu bağlanmıştır. Yapay meme uçlarına merkezlerinden $3 \mathrm{~mm}$ çaplı delik açılarak su emiş ağızları 
oluşturulmuştur. Denemelerde homojenliği sağlamak amacı için aynı kauçuk tip meme lastikleri kullanılmıştır.

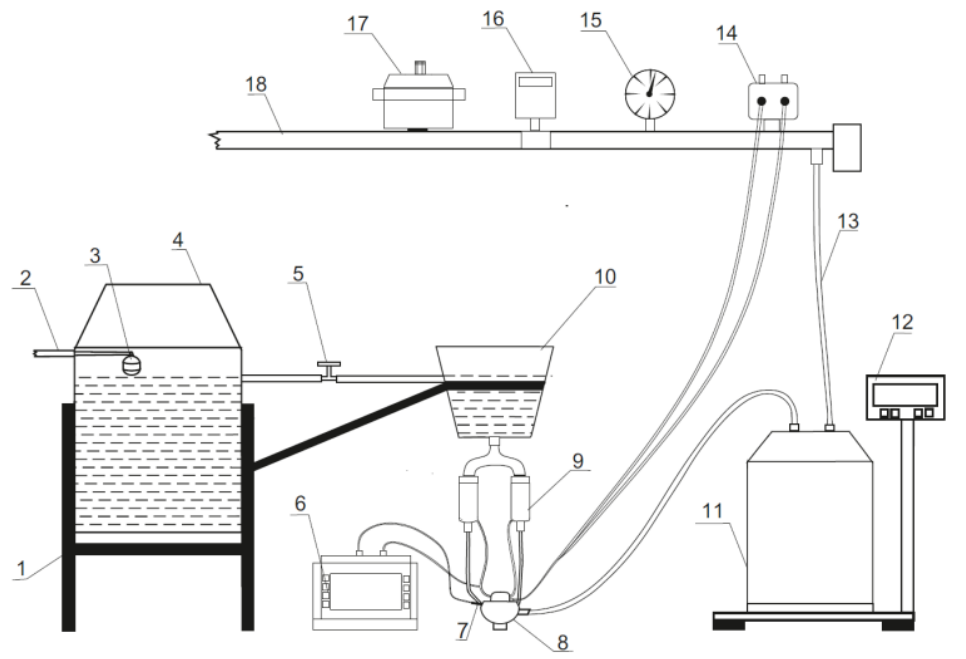

1- Su deposu taşıma şasisi

2- Su girişi hattı

3- Su seviye şamandırası

4- Su deposu

5- Musluk

6- Nabız-vakum kayıt cihazı

7- Vakum ölçüm iğnesi

8- Süt pençesi

9- Sağım başlı̆̆

10- Meme modeli

11- Güğüm

12- Terazi

13- Vakum hortumu

14- Elektronik pulsatör

15- Analog vakummetre

16- Elektronik vakummetre

17- Vakum regülatörü

18- Ana vakum hatt1

Şekil 1. Simülasyon sağım sistemi deney düzeneğinin şematik görünüşü

Sağım başlıkları sağım pozisyonunda olacak şekilde yapay meme uçlarına takılmıştır. Meme lastiğinin paslanmaz kılıf dışında kalan ve kısa süt hortumu olarak bilinen bölümüne özel olarak imal edilmiş bir vakum basıncı ölçüm iğnesi (7) bağlanmıştır. Sağım başlığına bağlanan ve ölçüme esas olan bir meme lastiğindeki kısa nabız hortum çıkışı ve vakum basıncı ölçüm adaptöründen çatal bağlantı ile bypass yapılarak vakum-nabız ölçüm cihazına (Exendis PT V) (6) bağlantı yapılmıştır. Vakum basıncı ölçüm adaptörünün amacı kısa süt hortumundan geçen su/süt akışını keserek vakumnabız ölçüm cihazına olası zararı önlemektir. Araştırmada $150 \mathrm{ml}$ (Pençe-1), $240 \mathrm{ml}$ (Pençe-2), 300 $\mathrm{ml}$ (Pençe-3), $340 \mathrm{ml}$ (Pençe-4) ve $550 \mathrm{ml}$ (Pençe-5) hacimlerinde 5 farklı tip süt pençesi kullanılmıştır (Şekil 2). Makinanın farklı çalışma vakumlarında inekler için esas alınan nabız sayısının (60 adet $\mathrm{dk}^{-1}$ ) değişmemesi için pnömatik pulsatör yerine elektronik pulsatör (14) kullanılmıştır. Sistemin vakum üretme grubu ise yarı sabit sistemli sağım makinası seçilmiştir. Makinanın ana vakum hattı (18) üzerine bir adet vakummetre (15) ve bir adet vakum regülatörü (17) yerleştirilmiştir. Denemelerin hassasiyeti için ana vakum borusuna bağlanan bir adet elektronik vakummetre (16) ve vakum-nabız cihazının ölçtüğü vakum değerleri karşılaştırılarak, sistemin ana çalışma vakumu kontrol edilmiştir. Her bir meme lastiği için yapılan denemelerde sağımdan alınan suyun miktarı için $20 \mathrm{~L}$ kapasiteli bir süt gügümü (11) kullanılmıştır. Süt güğümü $1 \mathrm{~g}$ ölçüm hassasiyetli $50 \mathrm{~kg}$ kapasiteye sahip dijital bir terazi (12) üzerine oturmaktadır.

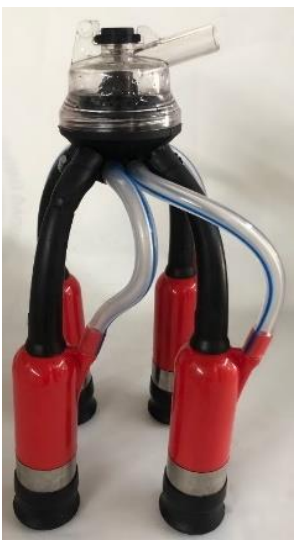

Pençe-1 $(150 \mathrm{ml})$

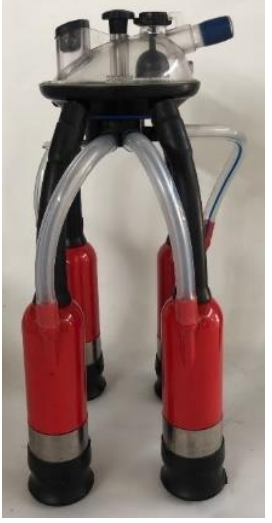

Pençe-2 $(240 \mathrm{ml})$

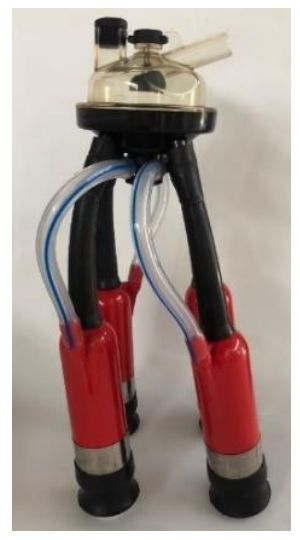

Pençe-3

$(300 \mathrm{ml})$

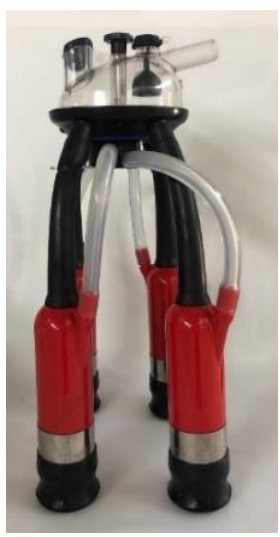

Pençe-4 $(340 \mathrm{ml})$

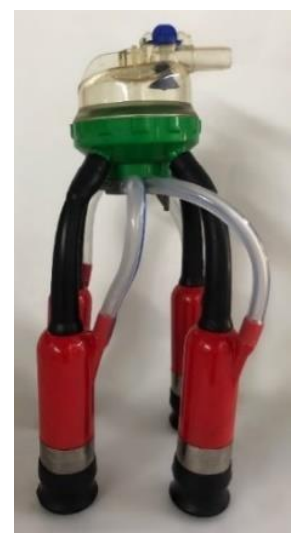

Pençe-5 $(550 \mathrm{ml})$

Şekil 2. Araştırmada kullanılan farklı hacimlerdeki süt pençeleri 
Simülasyon sağım sisteminde gügüm (sütün boşaltılma seviyesi esas alınacak şekilde), alçak süt hatlı sağım için süt pençesi seviyesinin $0,7 \mathrm{~m}$ altına, yüksek süt hatlı da ise sağım platformundan 1,8 m yükseğe yerleştirilmiştir. Su debisi, deney sırasında gügüme toplanan su miktarı kayıtlarından hesaplanmıştır.

Deneyler süresince vakum hatt1, nabız bölümündeki nabız-vakum ve kısa süt hortumu içindeki vakum değerleri kaydedilmiştir. Beş farklı hacimdeki süt pençeleri üzerinde aşağıdaki gibi değişik çalışma basınçları aşamaları gerçekleştirilmiştir:

- 41, 44 ve $47 \mathrm{kPa}$ basınçta çalışan ASH sağım sistemi

- $50 \mathrm{kPa}$ basınçta çalışan YSH sağım sistemi

Araştırmadaki dört farklı çalışma basıncının her aşamasında su (dinamik sağım deney sıvısı) akış hızları 0, 0,7, 2,7, 4,7, 6,6, 8,3 $\mathrm{kg} \mathrm{dk}^{-1}$ olarak ayarlanmıştır. Su debisi ayarlaması için yapay memenin altına küresel vana yerleştirilmiş̧ir. Vananın açma-kapama kolu arka hizasına dairesel bir malzeme monte edilerek, çok sayıda yapılan ön testler ile istenilen debiye uygun kol açıları belirlenmiş ve dairesel malzeme üzerinde ölçü çizgileri oluşturulmuştur. Belirlenen su debileri bu malzeme üzerinde oluşturulan ölçü çizgileri temel alınarak gerçekleştirilmiştir.

Ülkemizdeki en iyi süt çiftliklerinde uzmanların bilgilerine göre ortalama en yüksek süt debisi 3,0-6,0 kg dk${ }^{-1}$ aralığındadır. TS ISO 6690:2007 (2014)'ye göre dinamik testlerde en yüksek süt debisi düşük verimli inekler $3 \mathrm{~kg} \mathrm{dk}^{-1}$, yüksek verimliler için ise $5 \mathrm{~kg} \mathrm{dk}^{-1}$ alınır. TS ISO 5707:2007 (2014) Annex (EK) C'ye göre deneylerde $4 \mathrm{~kg} \mathrm{dk}^{-1}$ en yüksek süt debisi için ortalama süt debisi $2,6 \mathrm{~kg} \mathrm{dk}^{-1}$ alınır. Pulsatör kayıt cihazı (vakum-nabız ölçer test cihazı) tarafından kaydedilen nabız odası vakum değişiklikleri grafiği TS ISO 5707:2007, 2014 ve TS ISO 6690:2007, 2014 ile uyumlu olarak işleme tabi tutulmaktadır. " $\mathrm{a}+\mathrm{b}$ " fazındaki ortalama pençe vakumu incelenen sürecin kriteri olarak kullanılmıştır (TS ISO 3918:2007, 2014) (Şekil 3). Ortalama pençe vakumu makinalı sağımın emme fazında sütün boşalması sırasında hayvanın meme başında aktif olan vakumdur.

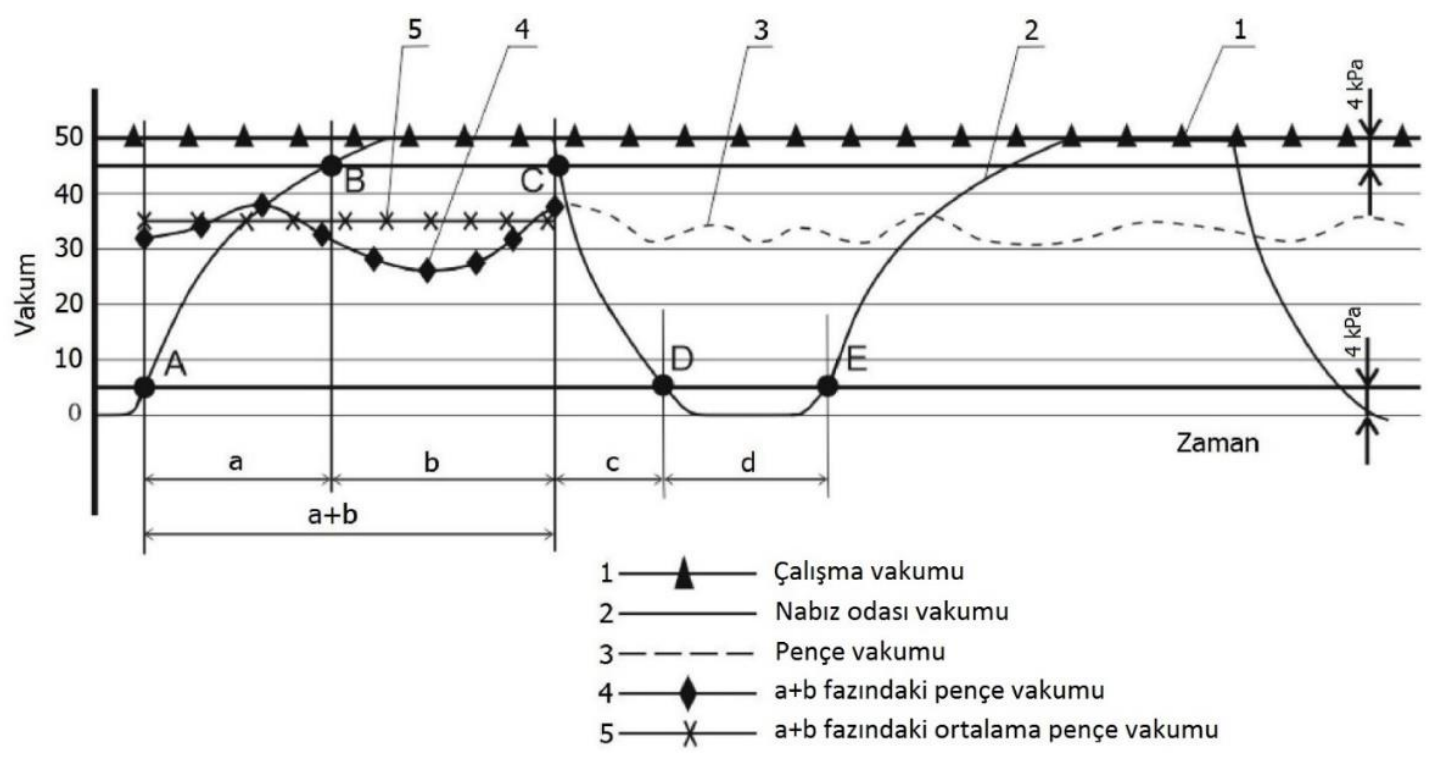

Şekil 3. Pulsatör test cihazından alınan nabız odası ve pençe vakumu değerlerinin analizi

\section{Bulgular ve Tartışma}

Alçak süt hatlı sağım sisteminin 41, 44 ve $47 \mathrm{kPa}$ çalışma vakumlarında farklı süt pençesi tipleri üzerinde değişik süt akış hızlarında yapılan deneme sonuçlarına göre $a+b$ süt alım evresindeki ortalama pençe vakum değişimleri sırasıyla Şekil 4, 5 ve 6'da verilmiştir.

Şekil 4 incelendiğinde; bütün pençelerin sistem kapalı olduğunda $\left(0 \mathrm{~kg} \mathrm{dk}^{-1}\right)$ ortalama pençe vakumları en uygun üst sınır olan $40 \mathrm{kPa}$ 'ın biraz üstünde olduğu görülmüştür. Pençe-1'de süt debisi $5,6 \mathrm{~kg} \mathrm{dk}^{-1}$ den daha yüksek olduğunda pençe vakumu alt sınır olan $32 \mathrm{kPa}$ 'dan daha düşük çıkmaktadır. $\mathrm{Bu}$ da sağım süresi uzunluğunu etkileyebilmektedir. Pençe-3 incelendiğinde, süt debisinin $0,2-5,4 \mathrm{~kg} \mathrm{dk}^{-1}$ arasında kaldığında, ortalama pençe vakumu standart değerlerin arasında olduğu belirlenmiştir. Pençe-4 ve Pençe-5'teki analiz sonuçlarına göre süt akış hızları sırasıyla 4,5 ile 
$6,1 \mathrm{~kg} \mathrm{dk}^{-1}$ den fazla olduğunda pençe vakumu kabul edilebilir aralıklardan (32-40 kPa) daha düşük bulunmuştur. Pençe-2'de ise süt debisi $6,4 \mathrm{~kg} \mathrm{dk}^{-1}$ üzerine çıktığında ortalama pençe vakumunun 32 $\mathrm{kPa}$ 'nn altına düştüğü görülmüştür. Bu sonuçlara göre, alçak süt hatlı sistemin $41 \mathrm{kPa}$ çalışma vakumunda uygun işletme koşullarında Pençe-2'nin en iyi sonuçları verdiği söylenebilir.

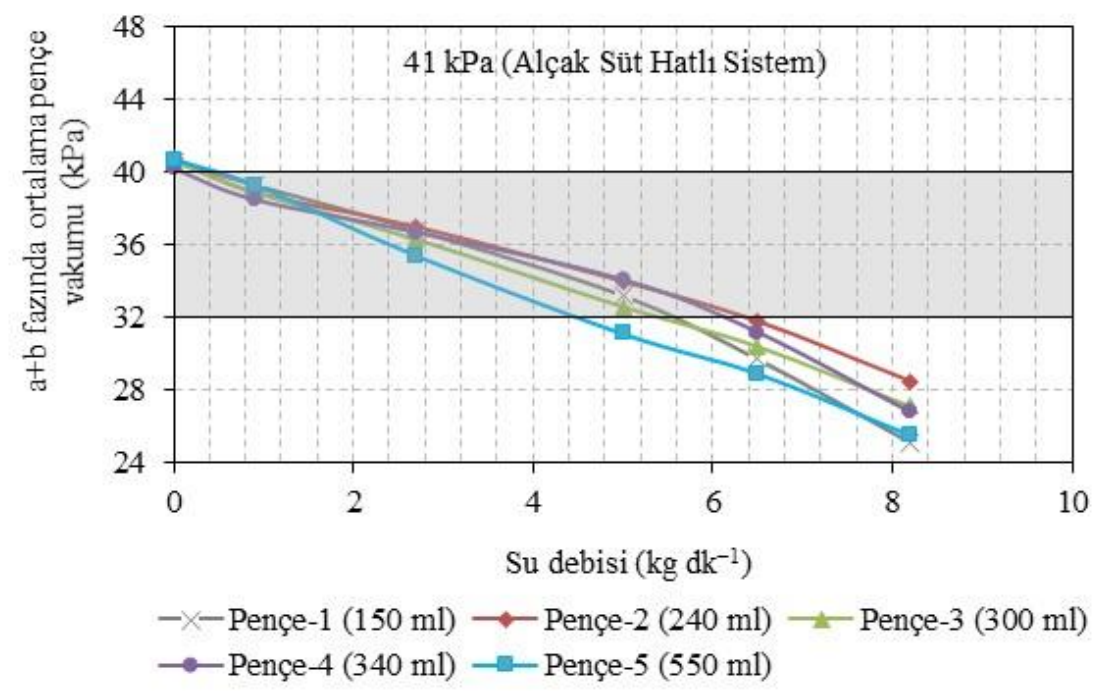

Şekil 4. $41 \mathrm{kPa}$ çalışma vakumunda farklı tip süt pençelerinin $\mathrm{a}+\mathrm{b}$ fazında ortalama pençe vakumu değişimleri

Şekil 5'te görüldüğg̈ gibi, Pençe-1 ve Pençe-3'ün araştırma sonuçlarına göre süt debileri sırasıyla $2,1 \mathrm{ve} 2,3 \mathrm{~kg} \mathrm{dk}^{-1}$, den daha düşük olduğunda ortalama pençe vakumu en uygun üst sinırdan daha yüksek çıkmaktadır. Bu da sağım başlangıcında ve sonunda hayvan meme başlarının vakumun negatif etkisine maruz kalacağı anlamına gelmektedir. Aynı pençelerde süt debisinin $6,5 \mathrm{~kg} \mathrm{dk}^{-1}$ 'den fazla olması durumunda ortalama pençe vakumu $32 \mathrm{kPa}$ 'ın altına düşmektedir. Pençe-4'te ise süt debisi $3 \mathrm{~kg} \mathrm{dk}^{-1}$, den daha düşük olduğunda pençe vakumunun üst sınırdan daha yüksek olduğu gözlenmiştir. Bu da sağım başlangıcı ve bitiminde hayvan meme sağlı̆̆ına olumsuz yönde etki etmektedir. Pençe-5 incelendiğinde en yüksek süt debisi aralığ $1,8-6,0 \mathrm{~kg} \mathrm{dk}^{-1}$ olduğunda ortalama pençe vakumu en uygun sınırlar içinde kalmaktadır. Pençe-2'nin ise 2,4-7,4 $\mathrm{kg} \mathrm{dk}^{-1}$ arasındaki en yüksek süt debilerinde ortalama pençe vakumu uygun sınırlar içerisinde kalmaktadır. Pençe-4'te 7,4 $\mathrm{kg} \mathrm{dk}^{-1}$ süt debisine kadar optimum alt sınır üzerinde kalarak uygun ortalama pençe vakumunu vermiştir. Buna göre $44 \mathrm{kPa}$ çalışma vakumunda Pençe-2 ve Pençe-4'ün en uygun ortalama pençe vakumu düzeylerini verdiği söylenebilir.

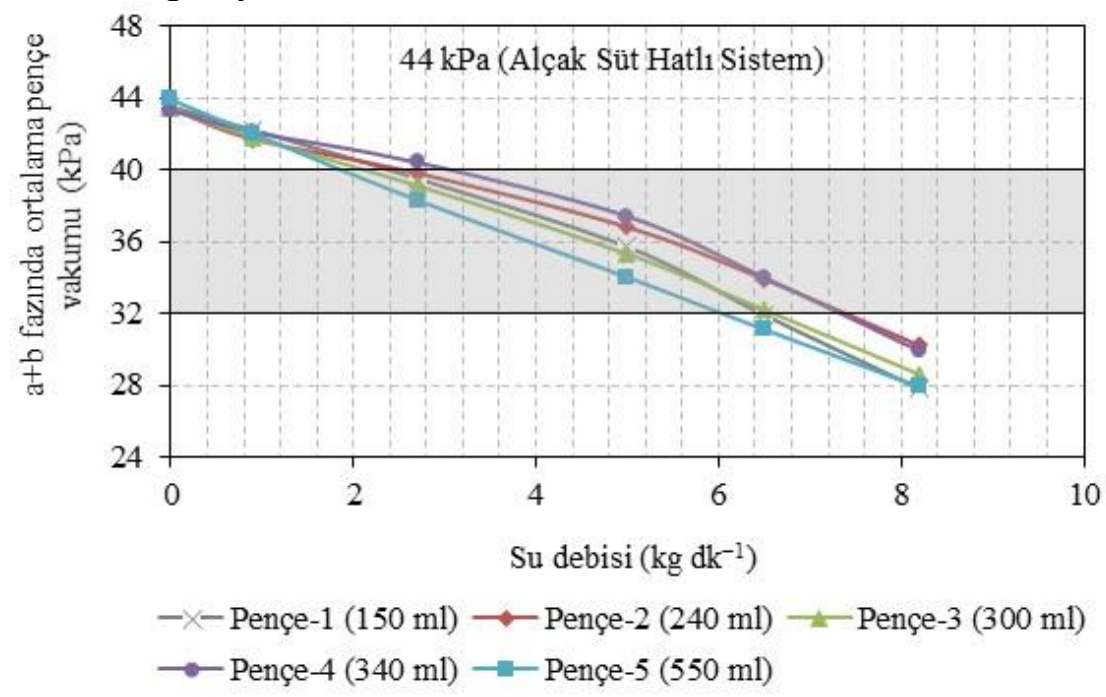

Şekil 5. $44 \mathrm{kPa}$ çalışma vakumunda farklı tip süt pençelerinin $\mathrm{a}+\mathrm{b}$ fazında ortalama pençe vakumu değişimleri 
Şekil 6' daki araştırma sonuçları incelendiğinde, Pençe-1'in süt debisi 3,4-6,8 $\mathrm{kg} \mathrm{dk}^{-1}$ aralığında olduğunda ortalama pençe vakumu en uygun sınırlar arasında kalmaktadır. Pençe-3 ve Pençe-4'le sağım yapıldığında süt akış hızları $5,0 \mathrm{~kg} \mathrm{dk}^{-1}$, den daha az olduğu durumlarda ortalama pençe vakumu kabul edilebilir sınırı aşmaktadır. Bu debiye kadar hayvanın meme başlarının sağım başlangıcı ve sonunda sürekli olarak yüksek vakumun olumsuz etkisine maruz kalacağı anlamına gelmektedir. 5,0$8,0 \mathrm{~kg} \mathrm{dk}^{-1}$ süt debisi aralıklarında ise Pençe-3 ve Pençe-4 en uygun sınırlar arasında kalmaktadır. Pençe-2'nin analiz sonuçlarına göre 4,4-8,3 $\mathrm{kg} \mathrm{dk}^{-1}$ süt debisi aralıklarında ortalama pençe vakumu uygun sınırların içinde kalmaktadır. Bu sonuç, Pençe-2, -3 ve -4'ün yüksek süt debisine sahip inekler için en uygun pençeler olabileceği düşünülmektedir. Diğer yandan Pençe-5'te ise, $2,7-6,5 \mathrm{~kg} \mathrm{dk}^{-1}$ süt debisi aralığında ortalama pençe vakumu standart sınırlarda (32-40 kPa) gözlenmiştir. Araştırma sonuçları Pençe-5 için bu basınçta sağım başlangıcı ve sonunda hayvanların meme başlarının negatif basıncın olumsuz etkisine diğer pençelere göre daha az maruz kalacağı sonucuna varılmıştır.

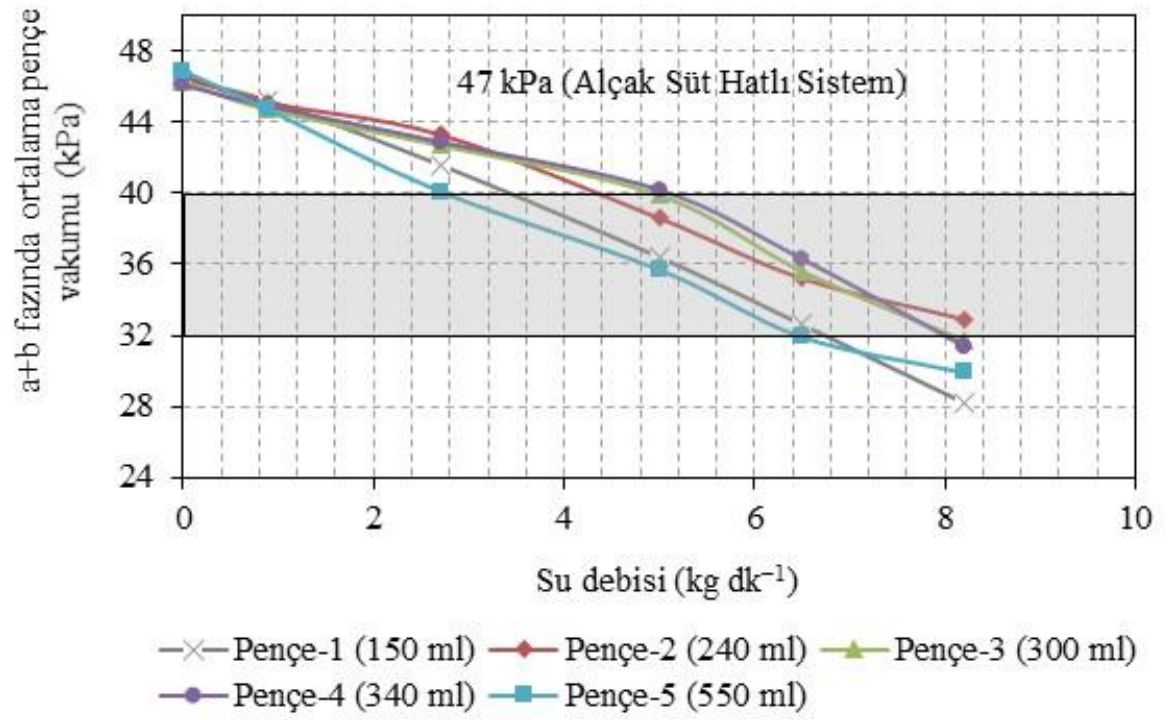

Şekil 6. $47 \mathrm{kPa}$ çalışma vakumunda farklı tip süt pençelerinin $\mathrm{a}+\mathrm{b}$ fazında ortalama pençe vakumu değişimleri

Yüksek süt hatlı sağım sisteminin $50 \mathrm{kPa}$ çalışma vakumunda farklı süt pençesi tipleri üzerinde değişik süt akış hızlarında yapılan deneme sonuçlarına göre $a+b$ süt alım evresindeki ortalama pençe vakumu değişimleri Şekil 7'de verilmiştir.

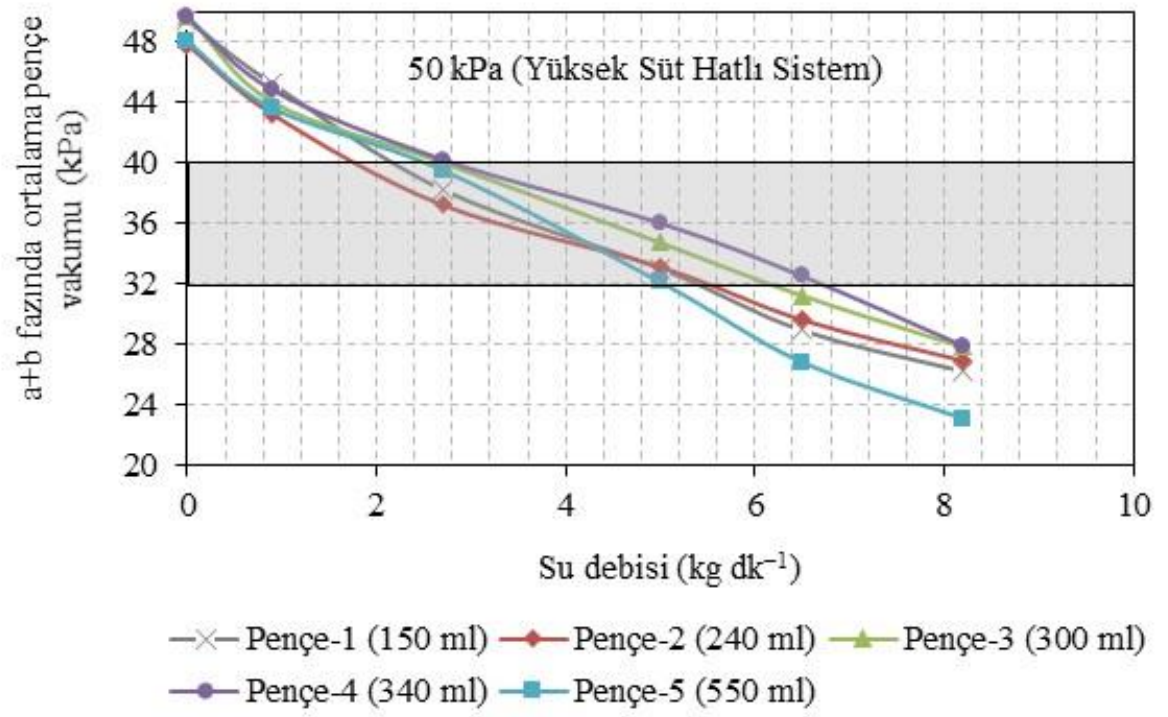

Şekil 7. $50 \mathrm{kPa}$ çalışma vakumunda farklı tip süt pençelerinin $\mathrm{a}+\mathrm{b}$ fazında ortalama pençe vakumu değişimleri 
Şekil 7 incelendiğinde, Pençe-1'in ölçüm sonuçlarına göre süt debisi $2,1 \mathrm{~kg} \mathrm{dk}^{-1}$ 'den daha az olduğunda, ortalama pençe vakumu en uygun üst sınırdan daha yüksek ölçülmüştür. Aynı pençede süt debisi $5,4 \mathrm{~kg} \mathrm{dk}^{-1}$, den daha yüksek olduğunda ise ortalama pençe vakumu en uygun alt sınırın altına düşmektedir. Pençe-2'deki süt debisi $1,7-5,5 \mathrm{~kg} \mathrm{dk}^{-1}$ aralığında olduğunda ortalama pençe vakumu uygun sınırlar arasında kalmıştır. Bu pençe için bu basınçta sağım başlangıcı ve sonunda hayvanların meme başlarının negatif basıncın olumsuz etkisine diğer pençelere göre daha az maruz kalacağı anlamına gelmektedir. Pençe-5'in araştırma sonuçlarına göre süt debisi 2,5-5,1 kg dk ${ }^{-1}$ aralığında ortalama pençe vakumu kabul edilebilir sınırlar içerisinde kalmaktadır. En yüksek süt debisi fazla olduğunda Pençe-5'in ortalama pençe vakumunun çok düşük olması nedeniyle sağım süresinin uzamasına sebep olacağı düşünülmektedir. Pençe-3 ve Pençe-4'ün süt akış hızlarının $2,7 \mathrm{~kg} \mathrm{dk}^{-1}$ 'den daha düşük olduğu durumlarda ortalama pençe vakumu değerleri üst sınırdan daha yüksek bulunmuştur. Söz konusu pençelerde süt akış hızlarının sırasıyla $6,1 \mathrm{ve} 6,7 \mathrm{~kg} \mathrm{dk}^{-1}$ 'den daha yüksek olması durumunda pençe vakumlarının kabul edilebilir alt sınırının altına düştüğü görülmektedir. Yüksek süt hatlı için $50 \mathrm{kPa}$ sistem çalışma basıncında ortalama pençe vakumu en uygun süt pençelerinin Pençe-2, Pençe-3 ve Pençe-4 olduğu düşünülmektedir.

$\mathrm{Bu}$ sonuçlara göre, alçak süt hatlı sistemin 41 ve $44 \mathrm{kPa}$ çalışma vakum vakumlarında Pençe2'nin, $47 \mathrm{kPa}$ çalışma vakumunda ise Pençe-5' in en uygun ortalama pençe vakum aralıklarını verdiği söylenebilir. Yüksek süt hatlı sistemdeki $50 \mathrm{kPa}$ çalışma vakumunda ise, Pençe-3 ve Pençe-4 en uygun ortalama pençe vakumları aralıkları sağlamıştır. Enokidani ve ark. (2016)'nın yaptıkları ıslak test araştırmasına göre yüksek süt hatlı sistemdeki $50 \mathrm{kPa}$ çalışma vakumunda ve $8,7 \mathrm{~kg} \mathrm{dk}^{-1}$ süt debisindeki ortalama pençe vakumunun $31,7 \mathrm{kPa}$ 'a düştüğü belirtilmiştir. Aynı araştırmacılar alçak hatlı sistemde ise $40 \mathrm{kPa}$ olan çalışma vakumunda ortalama pençe vakumunun aynı debi sınırında 39,7 $\mathrm{kPa}$ 'a düştügünü belirlemişlerdir. Buna göre bu çalışmamızda yüksek hatlı sistem için Pençe-3 ve Pençe-4'ün kabul edilebilir sınıra yakın ortalama pençe vakumlarını vermesi, araştırma sonuçlarımızı desteklemektedir. Diğer yandan alçak hatlı sistemde ise, Pençe-2'nin 6,4 $\mathrm{kg} \mathrm{dk}^{-1}$ debisine kadar kabul edilebilir sınır aralığında ortalama pençe vakumunu vermesi, bu pençenin tavsiye edilmesini desteklemektedir. Reinemann ve ark. (2007) nın ıslak testle yaptıkları araştırmaya göre, sistem basıncı $44 \mathrm{kPa}$ olduğunda ineklerin geneline ait ortalamada en yüksek süt debisi için $\left(1,9 \mathrm{~kg} \mathrm{dk}^{-1}\right)$ ortalama pençe vakumunu $42,5 \mathrm{kPa}$, ineklerin $\% 10$ 'nuna ait en yüksek süt debisi için $\left(3,9 \mathrm{~kg} \mathrm{dk}^{-1}\right)$ ortalama pençe vakumunu $40,7 \mathrm{kPa}$ ve ineklerin \%5'ine ait en yüksek süt debisi için $\left(5,8 \mathrm{~kg} \mathrm{dk}^{-1}\right)$ ortalama pençe vakumunu $38,6 \mathrm{kPa}$ olarak belirlemişlerdir. Araştırmacıların bu sonuçlarına benzer çalışma sonuçlarımız Pençe-2 ve Pençe-4'te daha uygun bulunmuştur. Öz ve ark. (2010) nın $40 \mathrm{kPa}$ sistem basıncındaki gerçek sağım koşullarında yaptıkları araştırmada ise, $300 \mathrm{ml}$ hacimdeki süt pençeli sağım denemelerinde 4,8 $\mathrm{L} \mathrm{min}^{-1}$ en yüksek süt debisinde "b" fazındaki ortalama pençe vakumunu $35,0 \mathrm{kPa}$ olarak belirlemişlerdir. Bu çalışmamızda kullanılan 240 ve $340 \mathrm{ml}$ hacimlere sahip Pençe-2 ve Pençe4, araştırmacıların sonuçlarına en yakın değerleri vermektedir. Bu da bu sistem basıncında Pençe-2'nin seçilmesini desteklemektedir.

\section{Sonuç ve Öneriler}

Araştırma sonucunda $41 \mathrm{kPa}$ çalışma basıncında Pençe-5 4,4 kg dk ${ }^{-1}$ debiye kadar, Pençe-2 6,4 $\mathrm{kg} \mathrm{dk}^{-1}$ debiye kadar standardın ön gördüğü alt sınır değere kadar $(32 \mathrm{kPa})$ uygun ortalama pençe vakum aralığ 1 verebilmektedir. $44 \mathrm{kPa}$ çalışma vakumunda ise, Pençe-2 ve Pençe-4 7,4 kg dk süt $^{-1}$ debisine kadar uygun pençe vakumları göstermiştir. $47 \mathrm{kPa}$ çalışma basıncında Pençe-2, -3 ve -4 çok yüksek süt debisine sahip inekler için $\left(4,4-8,3 \mathrm{~kg} \mathrm{dk}^{-1}\right)$ uygun olabileceği düşünülmektedir. Ancak bu basınç için Pençe-5 2,7-6,5 $\mathrm{kg} \mathrm{dk}^{-1}$ en yüksek süt debisi aralıklarında en uygun ortalama pençe vakumu sağlamıştır. Yüksek süt hatlının $50 \mathrm{kPa}$ sistem basıncında $1,7-5,5 \mathrm{~kg} \mathrm{dk}^{-1}$ süt debisi aralıklarında Pençe-2, 2,7-6,1 $\mathrm{kg} \mathrm{dk}^{-1}$ süt debisi aralıklarında Pençe-3 ve 2,7-6,7 $\mathrm{kg} \mathrm{dk}^{-1}$ süt debisi aralıklarında Pençe-4 en uygun ortalama pençe vakum değerlerini vermiştir.

Reinemann ve ark. (2007), sistem çalışma vakumunun kullanıcının sağım sırasında istenilen ortalama pençe vakumu aralığına ulaşması için ayarlandığı bir parametre olduğunu bildirmektedir. Sabit sistem vakumu ile değişken ortalama pençe vakumu arasındaki farkı etkileyen 3 ana faktör vardir: 
1- Sistem konfigürasyonu (uzun süt borusu uzunluğu ve çap1, uzun süt borusundaki bağlantılar ve sürtünme kayıplarını etkileyen diğer parametreler),

2- Sütün uzun süt borusundan akış hızı (artan süt akışı genellikle sistem ve pençe vakumu arasındaki fark1 arttırır),

3- Sağım ünitesine giren serbest havanın debisi (artan hava girişi aynı zamanda sistem ve pençe vakumu arasındaki fark1 arttırır).

Yukarıda belirtilen faktörler de göstermektedir ki, sağımın uygun pençe vakum aralıklarında hassas, hızlı ve eksiksiz şekilde yapılabilmesini etkileyen birçok unsur vardır. Enokidani ve ark. (2016) nın alçak ve yüksek süt hatlı 1slak simülasyon test çalışmalarındaki farklı iç çap ve uzunluklara sahip uzun süt hortumlarının ortalama pençe vakumuna etkisini araştırmaları, sağım makinalarında sağımı etkileyebilecek birçok farklı unsurun daha araştırılması gerektiğini göstermektedir. $\mathrm{Bu}$ araştırma bu unsurlar arasında önemli olabileceği düşünülen süt pençesi hacim değişikliğinin ortalama pençe vakumuna etkisini ortaya koyabilmek açısından araştırmacılara, üretici firmalara ve süt hayvancılığı işletmelerine yararlı kaynak olacağı inancındayız. Alçak süt hatlı sağım makinalarında önerilen pençe vakum aralıkları için en uygun çalışma basıncının, Avrupa ülkelerinde $41 \mathrm{kPa}$, Kuzey Amerika'da ise $44 \mathrm{kPa}$ seçilmesi tavsiye edilebilir.

\section{Not}

$\mathrm{Bu}$ çalışma Bursa Uludağ Üniversitesi Ziraat Fakültesi Biyosistem Mühendisliği Bölümü lisans öğrencilerinin "Tasarım Proje" tezinin bir bölümünü kapsamakta ve Çanakkale Onsekiz Mart Üniversitesi'nde 04-06 Eylül 2019 tarihlerinde düzenlenen 32. Tarımsal Mekanizasyon ve Enerji Kongresinde poster olarak sunulmuş ve kongre bildiri kitabında özeti yayınlanmıştır.

\section{Kaynaklar}

Andersons, E., Laurs, A., Priekulis, J., 2014. Studies on liner vacuum in high and low level milking systems. Engineering for Rural Development, Jelgava. 29-30.05.2014, p. 94-98.

Enokidani, M., Kuruhara, K., Kawai, K., 2016. Analysis of factors affecting milking claw vacuum levels using a simulated milking device. Animal Sci. J. 87: 848-854.

Jones, G.M., 1999. The role of milking equipment in mastitis. Virginia Cooperative Extension. http://pubs.ext.vt.edu/ 404/404-742/404-742.html Erişim: Nisan 2018.

Öz, H., 2003. Süt sağma makinalarında bazı teknik özelliklerin performans değerlerine etkisinin laboratuvar koşullarında belirlenmesi. Doktora Tezi, Ege Üniversitesi, Fen Bilimleri Enstitüsü, Tarım Makinaları Anabilim Dalı, 134 s., İzmir.

Öz, H., Rose-Meierhöfer, S., Ströbel, U., Ammon, C., 2010. Comparison of the vacuum dynamics of conventional and quarter individual milking systems. J. Agric. Sci. 16: 162-168.

Rasmussen, M.D., Madsen, N.P. 2000. Effects of milkline vacuum, pulsator airline vacuum, and cluster weight on milk yield, teat condition and udder health. J. Dairy Sci. 83: 77-84.

Rasmussen, M.D., Reinemann, D.J., Mein, G.A. 2003. Measuring vacuum in milking machines. Bulletin No. 381/2003, International Dairy Federation, Brussels, pp. 20-32. Belgium.

Reinemann, D.J., Rasmussen, M.D., Mein, G.A., Frimer, E.S. 1996. Test equipment and it's application for measuring vacuum in the short milk tube. http://www.uwex.edu/uwmril/pdf/MilkMachine/ PerformanceTesting/96_ASAE_963018_Test_Equipment_SMT_vac.pdf, Erişim: Mart 2018.

Reinemann, D.J., Mein, G.A., Rasmussen, M.D., Ruegg, P.L. 2005. Evaluating milking performance. Bulletin of the International Dairy Federation. No. 396, 1-24.

Reinemann, D.J, Schuring, N., Bade, R.D., 2007. Methods for measuring and interpreting milking vacuum. In: Proceedings of Sixth International Dairy Housing Conference. 16-18 June, Minneapolis, Minnesota, USA.

Rose-Meierhöfer, S., Hoffmann, G., Öz, H., Ströbel, U., Ammon, C., 2010. Milking-time tests in conventional and quarter-individual milking systems. Landbauforschung-vTI Agriculture and Forestry Research. 60: $11-15$.

TS ISO 3918:2007, 2014. Süt Sağım Makine Tesisleri-Terimler. Türk Standartları Enstitüsü, 19 s., Ankara.

TS ISO 5707:2007, 2014. Süt Sağım Makine ve Tesisleri-Yapım ve Performans. Türk Standartları Enstitüsü, 47 s., Ankara. 
ÇOMÜ Zir. Fak. Derg. (COMU J. Agric. Fac.)

2020: 8 (2): 465-473

ISSN: $2147-8384$ / e-ISSN: 2564-6826

doi: $10.33202 /$ comuagri.659663

TS ISO 6690:2007, 2014. Süt Sağım Makine Testleri-Mekanik Deneyler. Türk Standartları Enstitüsü, 34s., Ankara.

Ünal, H., Özgür, F., Bilgin, A.S., Ural, Ş., 2018. Alçak ve yüksek süt hatlı sağım sistemlerinde çalışma vakumu ve süt debisi değişimlerinin memebaşı ucu vakum basıncına etkisi. Tarım Makinaları Bilimi Dergisi. 14 (3): 163-169. 